\title{
Inflammatory pseudotumor of the pineal region: First reported case
}

\author{
PING-DING KUANG ${ }^{1 *}$, QING-HAI LI ${ }^{*}$, ZI-YU LIU ${ }^{2}$, JIN-LONG TANG $^{2}$, \\ FEI DONG ${ }^{1}$, YING WANG ${ }^{1}$ and XIU-LIANG ZHU $^{1}$
}

\begin{abstract}
Departments of ${ }^{1}$ Radiology and ${ }^{2}$ Pathology, The Second Affiliated Hospital of Zhejiang University School of Medicine, Hangzhou, Zhejiang 310009, P.R. China
\end{abstract}

Received December 23, 2014; Accepted January 14, 2016

DOI: $10.3892 / \mathrm{ol} .2016 .4212$

\begin{abstract}
Inflammatory pseudotumors originating in the central nervous system (CNS) are quite rare. To the best of our knowledge, the present study reports the first case of a inflammatory pseudotumor that developed in the pineal region, and describes the neuroimaging, morphological and immunohistochemical findings. A 53-year-old male presented with hearing loss that had been apparent for 1 year and blurred vision that had persisted for 10 months. Magnetic resonance imaging (MRI) demonstrated a homogeneously-enhanced mass in the pineal region and obstructive hydrocephalus. A pathological examination revealed that the lesion was comprised predominantly of spindled cells in a collagenous background, with dense infiltrates of small lymphocytes, plasma cells and uninucleated histiocytes. Immunopositivity for cluster of differentiation (CD)138 was noted. Immunohistochemical staining showed that the cells were immunonegative for glial fibrillary acidic protein, S-100, placental alkaline phosphatase, neurofilament and Pit-Oct-Unc class 5 homeobox 1 . The Ki-67 labeling index was $<5 \%$. The lymphocytic infiltrates consisted of CD3- and CD43-positive T-cells, and CD20- and CD79A-positive B-cells. Plasma cells displayed polytypic reactivity for immunoglobulin $\kappa$ and $\lambda$ light chains. Based on the MRI and the morphological and immunohistochemical analysis, a diagnosis of an inflammatory pseudotumor was formed. The patient underwent a surgical resection of the tumor and currently has a good prognosis.
\end{abstract}

\section{Introduction}

The normal pineal gland secretes melatonin, which is involved in diurnal rhythms, and is located in the supratentorial

Correspondence to: Dr Xiu-Liang Zhu, Department of Radiology, The Second Affiliated Hospital of Zhejiang University School of Medicine, 88 Jiefang Road, Hangzhou, Zhejiang 310009, P.R. China E-mail: zhuxiul@yeah.net

*Contributed equally

Key words: pineal region, inflammatory pseudotumor, plasma cells, magnetic resonance imaging, pathology midline, above the superior colliculi and below the splenium of the corpus callosum and the vein of Galen (1). Pineal region neoplasms include germinoma, teratoma, pinealocytoma and meningioma; these tumors are infrequently occurring lesions that account for $<1 \%$ of all primary intracranial tumors in adults and $3-8 \%$ in the pediatric population $(2,3)$.

Inflammatory pseudotumor is a pathological term that describes a reactive, inflammatory non-neoplastic tumor that typically occurs in the lungs, omentum, mesentery, retroperitoneum, orbital cavities, upper respiratory tract or genitourinary tract. Primary intracranial involvement is extremely rare (4). The histopathology of an inflammatory pseudotumor consists of a collagenous stroma and an inflammatory infiltrate of mononuclear elements (5). Due to the rarity of inflammatory pseudotumors that occur in the central nervous system, forming an accurate diagnosis by MRI scans is challenging. According to previous studies, surgical removal of the pseudotumor and treatment of the forhydrocephalus were performed in the majority of cases, and the outcomes were generally good $(6,7)$. The current study reports the case of a patient with an inflammatory pseudotumor of the pineal region, and to the best of our knowledge, it is the first reported case of an inflammatory pseudotumor in this location.

\section{Case report}

A 53-year-old man presented to The Second Affiliated Hospital of Zhejiang University School of Medicine (Hangzhou, Zhejiang, China) with hearing loss that had been apparent for 1 year and blurred vision that had persisted for 10 months. The patient was conscious and well-oriented, and normal pupil reactions were present. The general physical examination was within normal limits and the neurological examination indicated clear and alert consciousness.

The routine laboratory investigations were within normal reference ranges. Brain magnetic resonance imaging (MRI) was performed using the 1.5T MRI scanner (Siemens Sonata, Erlangen, Germany) prior to and following the intravenous administration of gadolinium contrast material. A well-defined mass in the pineal region was revealed, which extended into the posterior third ventricle and was compressing the tectal plate from above. The mass was isointense on non-contrast 

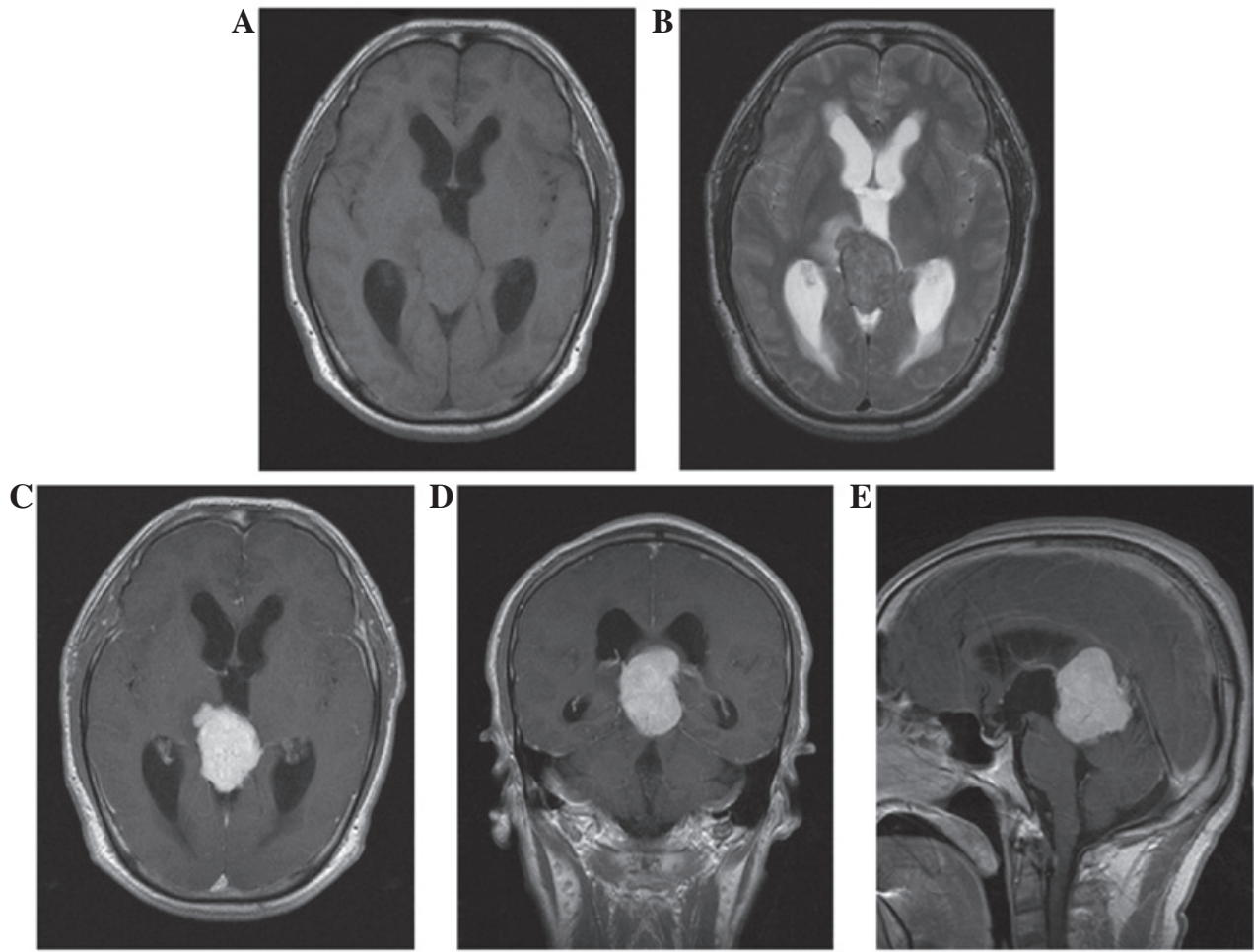

Figure 1. MR images showing a well-defined mass involving the pineal region with resultant hydrocephalus. The mass was (A) isointense on axial T1-weighted imaging and (B) hyperintense on axial T2-weighted imaging. On (C) axial, (D) coronal and (E) sagittal post-contrast T1-weighted MR images, contrast enhancement of the mass was avid.
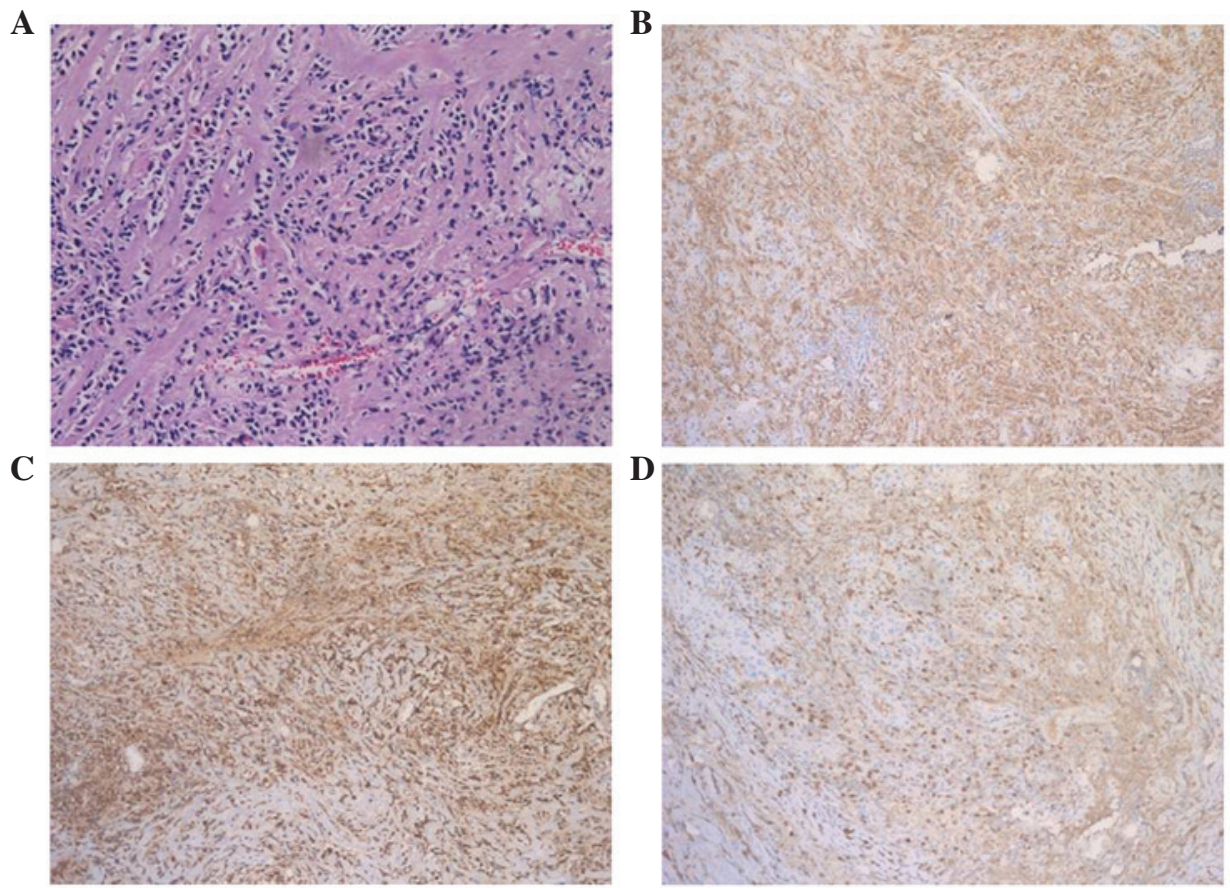

Figure 2. Microscopic findings. (A) Photomicrograph showing an inflammatory cell-rich lesion with a small number of spindle cells set in a collagenous stroma. The inflammatory infiltrate consisted of a mixture of plasma cells, lymphocytes and histiocytes, and no definite tumor cells were found (hematoxylin and eosin staining; original magnification, x200). (B) Plasma cells showing immunopositivity for cluster of differentiation 138 (original magnification, x100). (C) Plasma cells showing polytypic reactivity for immunoglobulin $\kappa$ light chains (original magnification, $x 100$ ). (D) Plasma cells showing polytypic reactivity for immunoglobulin $\lambda$ light chains (original magnification, $\mathrm{x} 100$ ).

T1-weighted images (Fig. 1A) and heterogeneously hyperintense on T2-weighted images (Fig. 1B), while homogeneous contrast enhancement of the mass lesion was observed following administration of gadolinium (Fig. 1C-E). A provisional diagnosis of pineal germinoma or pinealocytoma was considered. 
A pathological examination revealed that the lesion was comprised predominantly of spindle cells in a collagenous background, with dense infiltrates of small lymphocytes, plasma cells and uninucleated histiocytes (Fig. 2A). There was no evidence of mitosis or necrosis. Immunopositivity for cluster of differentiation (CD)138 was noted (Fig. 2B). Specific acid-fast bacillus staining for fungus and mycobacteria was negative.

Tumor samples were formalin-fixed and paraffin-embedded, and cut into $4-\mu \mathrm{m}$ thick sections that were stained using standard hematoxylin and eosin methods. Immunohistochemical staining was performed using a Ventana NexES automated immunostainer (Ventana Medical Systems, Inc., Tuscon, AZ, USA). The antibodies used included rabbit anti-human S-100 protein polyclonal antibody (catalog no. ZA-0225; dilution, 1:500), rabbit antihuman CD3 monoclonal antibody (catalog no., ZA-0503; dilution, 1:100), rabbit anti-human CD20 monoclonal antibody (catalog no., ZA-0549; dilution, 1:200), mouse antihuman CD43 monoclonal antibody (catalog no., ZM-0048; dilution, 1:100), rabbit anti-human CD79A monoclonal antibody (catalog no., ZA-0293; dilution, 1:150), mouse antihuman CD138 monoclonal antibody (catalog no., ZM-0459; dilution, 1:50), mouse anti-human Igк monoclonal antibody (catalog no., ZM-0160; dilution, 1:200), rabbit anti-human Ig $\lambda$ monoclonal antibody (catalog no., ZM-0180; dilution, 1:200), mouse anti-human Ki-67 monoclonal antibody (catalog no., ZM-0167; dilution, 1:100), mouse anti-human neurofilament (NF) monoclonal antibody (catalog no., ZM-0198; dilution, 1:200) and mouse antihuman Pit-Oct-Unc class 5 homeobox 1 (Oct3/4) monoclonal antibody (catalog no., ZM-0233; dilution, 1:100). All antibodies were purchased from Zhongshan Golden Bridge Biotechnology Co., Ltd. All tissue sections underwent heat-induced antigen retrieval. The results showed that the cells were immunonegative for glial fibrillary acidic protein, S-100, placental alkaline phosphatase, NF and Oct3/4. NF immunostaining is common in diagnostic neuropathology, and is useful for differentiating between neurons, which express NF, and glia, which do not express NF (8). Oct3/4, a member of the Pit-Oct-Unc domain transcription factors family, is normally expressed in adult and embryonic stem (ES) cells, so may be expressed in malignant tumors (9). Increased Oct $3 / 4$ expression increases the malignant potential of ES cell-derived tumors, whereas Oct3/4 inactivation induces the regression of the malignant component (10).

The Ki-67 labeling index was $<5 \%$. The lymphocytic infiltrates consisted of CD3- and CD43-positive T-cells, and CD20- and CD79A-positive B-cells. Plasma cells displayed polytypic reactivity for immunoglobulin $\kappa$ (Fig. 2C) and $\lambda$ (Fig. 2D) light chains.

Based on the MRI, and the morphological and immunohistochemical analysis, a final diagnosis of an inflammatory pseudotumor was formed. In May 2014, the patient underwent surgical resection of the tumor at The Second Affiliated Hospital of Zhejiang University School of Medicine. Following the surgery, the patient has not undergone any further treatment, and at 20 months of follow-up, there is no evidence of recurrence with the patient continuing to attend regular follow-up sessions.

\section{Discussion}

Inflammatory pseudotumors form a heterogenous disease group with an unsettled pathogenesis (11). The tumors contain fibrosis and inflammatory cells, with irregularly scattered infiltration by macrophages, plasma cells and lymphocytes, and are possibly as a result of inflammation. Furthermore, inflammatory pseudotumors may also be caused by infections $(12,13)$.

The radiologists in the present study could not precisely diagnose the mass as an inflammatory pseudotumor, and the MRI images did not provide a specific pretreatment diagnosis. On imaging, the inflammatory pseudotumor appeared as a heterogeneously enhancing mass originating from the pineal region. The secondary finding of obstructive hydrocephalus was observed, similar to that found with other masses in this location. To the best of our knowledge, no cases of inflammatory pseudotumors developing in the pineal region, which may have assisted in forming a diagnosis, are recorded in the literature, and the histopathology was the mainstay in establishing the diagnosis.

According to previous studies, surgical removal of the pseudotumor and treatment of the forhydrocephalus were performed in the majority of cases, and the outcomes were generally good $(6,7)$. Due to the rarity of inflammatory pseudotumors that occur in the pineal region, clinical experience of this entity remains limited and further detailed studies are required to provide a standardization of therapy.

In conclusion, inflammatory pseudotumors occurring in the central nervous system are extremely rare. To the best of our knowledge, there have no previously reported cases of an inflammatory pseudotumor originating in the pineal region. Although rare, a diagnosis of an inflammatory pseudotumor should be considered when a tumorous lesion is noted in the pineal region. A correct histopathological diagnosis is required in order for an appropriate therapeutic regimen to be selected for the lesion.

\section{Acknowledgements}

The present study was supported by the Zhejiang Education Fund (Hangzhou, China; grant no., Y201330158).

\section{References}

1. Dahiya S and Perry A: Pineal tumors. Adv Anat Pathol 17: 419-427, 2010.

2. Smith AB, Rushing EJ and Smirniotopoulos JG: From the archives of the AFIP: Lesions of the pineal region: Radiologic-pathologic correlation. Radiographics 30: 2001-2020, 2010.

3. Yousem DM and Grossman RI (eds): Neoplasms of the brain. In: Neuroradiology: The Requisites. 3rd edition. Mosby, Philadelphia, pp94-98, 2010.

4. Swain RS, Tihan T, Horvai AE, et al: Inflammatory myofibroblastic tumor of the central nervous system and its relationship to inflammatory pseudotumor. Hum Pathol 39: 410-419, 2008.

5. Coffin CM, Watterson J, Priest JR and Dehner LP: Extrapulmonary inflammatory myofibroblastic tumor (inflammatory pseudotumor). A clinicopathologic and immunohistochemical study of 84 cases. Am J Surg Pathol 19: 859-872, 1995.

6. Yavuzer D, Dalbayrak S, Oz B, Yilmaz M and Akansel G: Intracranial inflammatory pseudotumor: Case report and review of the literature. Clin Neuropathol 29: 151-155, 2010.

7. Suri V, Shukla B, Garg A, Singh M, Rishi A, Sharma MC and Sarkar C: Intracranial inflammatory pseudotumor: Report of a rare case. Neuropathology 28: 444-447, 2008. 
8. Lee VM and Andrews PW: Differentiation of NTERA-2 clonal human embryonal carcinoma cells into neurons involves the induction of all three neurofilament proteins. J Neurosci 6: 514-521, 1986.

9. Looijenga LH1, Stoop H, de Leeuw HP, de Gouveia Brazao CA, Gillis AJ, van Roozendaal KE, van Zoelen EJ, Weber RF, Wolffenbuttel KP, van Dekken H, et al: POU5F1 (OCT3/4) identifies cells with pluripotent potential in human germ cell tumors. Cancer Res 63: 2244-2250, 2003.

10. Gidekel S, Pizov G, Bergman Y and Pikarsky E: Oct-3/4 is a dose-dependent oncogenic fate determinant. Cancer Cell 4: 361-370, 2003.
11. Lui PC, Fan YS, Wong SS, Chan AN, Wong G, Chau TK, Tse GM, Cheng Y, Poon WS and Ng HK: Inflammatory pseudotumors of the central nervous system. Hum Pathol 40: 1611-1617, 2009.

12. Fukunaga A, Yoshida K, Otani M, Ogawa Y, Horiguchi T, Ishihara $\mathrm{M}$, Toya $\mathrm{S}$ and Kawase T: Plasma cell granuloma extending from the extracranial to the intracranial space associated with Epstein-Barr virus infection. Neurol Med Chir (Tokyo) 38: 292-296, 1998.

13. Jung TY, Jung S, Lee MC, Moon KS, Kim IY, Kang SS and Kim SH: Hemorrhagic intracranial inflammatory pseudotumor originating from the trigeminal nerve: A case report. J Neurooncol 76: 139-142, 2006. 